\title{
Community Perception and Indigenous Adaptive Response to Climate Variability at Tehuledere Woreda, South Wollo
}

\section{Mohammed Seid}

Arbaminch University, Arbaminch , Ethiopia

\begin{abstract}
Climate variability and extreme events have wide range economic, social and environmental impacts. In adaptation of these impacts, it is very important to assess and change the perception and awareness level of local community to climate variability and adaptation responses. Assessing the indigenous adaptation mechanisms and adaptation capacity is the integral part in addressing the adverse consequences of climate variability. There was no study, which assessed the adaptation to climate variability with integrating community perception in the study area. Thus, this study was aimed to fill this gap. The study has shown that, majority of participants were observed the existence of climate variability and indicators, But significant number of participants failed to perceive the causes of the variability. The effects of climate variability in the study area are land degradation, deforestation, decline of crop production, death of livestock, loss of grazing land, and destruction of infrastructures. The local communities have own adaptation methods, which include, production of different crops, planting of special variety crops, using of natural and chemical fertilizers, irrigation farming, planting of trees, and soil conservation. Adjusting the production season with the variability of climate is other cope up mechanism of farmers. The participants had problems with materials, financial and training supports from NGOs and governments.
\end{abstract}

Key words: climate variability, community perception, adaptation

\section{BACK GROUND OF THE STUdY}

The United Nations Environment Programme (UNEP) report has shown that, many of the continental regions have experienced a sharp seasonal and annual rainfall variation and temperature variation plus with extreme events (flood, storms and drought). According to the report some areas hit by high rainfall and others areas by the shortage of rainfall and its outcomes. This fluctuation and variability of climate patterns return extreme events and which brings serious hardship on the human and natural systems (UNEP, 2006). According to the UN International Strategy for Disaster Reduction (UNISDR) report, over the period 1991-2005, 3,470 million people were affected by extreme events of climate, 960,000 people died, and economic losses were US\$1,193 Billion (UNISDR, no date). 
Climate variability will affect all countries, but people in the poorest countries and poor people in richer countries are disproportionately affected by it. This is, due to poor agricultural practices, weak economic status, inadequate health services, low saving capacity and low level of technology development for mitigation and adaptation(Ziervogel, G. and Calder, R. 2003, and Belay, n.d.,). The likelihood of increased climate variability and climate extremes are expected to reduce incomes and increase illness and death rates in many developing countries. Africa, small island states, and Asian are likely to be particularly affected by climate variability (IPCC, 2007). Generally the statistics show that, $90 \%$ of all people killed by disasters between 1970 and 1999 were victim of climate-related hazards (IPCC, 2001 quoted in Thomalla et al., 2006). It Increasesheat waves, floods, storms, fires and droughts which resulted in malnutrition and food insecurity. In addition to these, it has also great impact on the world ecosystems, and biodiversity. (Richardson et al., 2009 cited in Jontzo, 2010).

No region is struck as severely by the impacts of climate variability as Africa ingeneral and Ethiopia in particular, due to very weak and less organized adaptation capacity (Block et al., 2008). Impacts of climate variability aren't recent phenomena in Ethiopia. For example, from 1540 to $1800 \mathrm{AD}, 26$ major famines and droughts, accompanied by the spread of human and livestock diseases, had been recorded. Similarly, the great Ethiopian famine (1889-92) is known for its epidemics and famine (McKee, 2008, and Pankhurst 1985, cited in Yohannes and Mebratu, 2009). The famines were not only due to shortage of rain but also too extended or excessive rain.Other climate related hazard in Ethiopia is flood, which occurred in different part of the country at different time, for example in1988, 1993, 1994, 1996 and 2006 which were caused for the loss of life and countless properties (NAPA, 2007).In addition to weak economic status, HIV/AIDS, endemic diseases, climate variability has become the common stress and headache to Ethiopiain generaland the study area in particular.Drought, flood, shortage of rainfall, unexpected heavy rainfall and other consequences of climate variability are not uncommon to Tehuledere woreda.There are different causes which exacerbate the vulnerability of theworeda to climate variability and extreme events. Dependence on seasonal rain fed subsistence agriculture, under development of water resources, low health service, high population growth rate, extensive cultivation, overgrazing, deforestation and soil erosion, low economic development, inadequate infrastructure exacerbate the variability and its impacts. Adaptation to climatic variability is a way of life and not new to Ethiopians and people of the study area. However, in the past or at present time there is a wide spread of traditional and cultural opinions among the Ethiopians in general and rural community in particular for the causes and consequences of climate variability. The rural community believed that, climate variability andits impacts are the acts of God against human sin (McKee, 2008, Mesfin, 1991 cited in Yohannes and Mebratu, 2009). Thus, assessing local community perception and awarenesslevel play its own paramount roles in adaptation of climate variability and to achieve the climate resilient and carbon free sustainable development in Ethiopia, especially in the study area. Public perception helps to arrive, good policies, strategies, action plans, activities to respond the economic and social impacts of climate variability at the local and national level (Palutikof et al., 2004). Therefore, this study was designed to address the local community's perception to climate variability, their responses, and adaptation capacity to its impacts at Tehuledere woreda, south wollo. 


\section{Objective OF the Study}

The general objective of this study was; to assess perception of the community and adaptive response to climate variability at Tehuledere woreda. The specific objectives of the study derived from the main objective were: description ofclimate variability, assessment of community perception to climate variability, and adaptive responses.

\section{BAsic Research Question}

To achieve objectives, the following key research questions were formulated.Q1. What is community's perception towards climate variability? Q2. What are the adaptive responses of local community to impacts of climate variability?Q3. How is community perception linked to their adaptive responses?

\section{MetHODOLOGY}

\section{Profile of the study area}

Tehuledere woreda is one of the twenty two districts of South Wollo in the Amhara National Regional State. The woreda is located at a distance of $430 \mathrm{~km}$ from Addis Ababa on the main road to Mekele. It shares immediate boarders in the North with Ambassel woreda, in the South with Dessie zuria woreda, in the East with Worebabo woreda and in the west with Kutaber and Ambassel woreda. The woreda has a total area of 44030 hectares and subdivided into nineteen rural and five small urban kebeles. Altitude of the woreda ranges from 1488-2900m.asl. It has 'Dega' (13\%), 'Weina Dega' (72\%), and 'Kolla' (15\%) agro-ecological zones.Its average annual rain fall is $1030 \mathrm{~mm}$ and has average temperature of $21^{\circ} \mathrm{C}$ per annum. It is themost populous area in Amhara region with total population 152,891. Out of the total land cover, 15937 ha is used for crop production, 736 ha for grazing, 14308 ha forest and bush land, 3800ha water body and 1000ha is wasteland. The average land holding per household is estimated as 0.5ha. Due tohigh population growth coupled with misuse of natural resources, poor diversification of livelihoods, and the relief nature of the area, the environment is strongly depleted, which returns high vulnerability of the community to climate variability and its adverse impacts. The location of sample kebeles are shown in the following figure (fig.1)

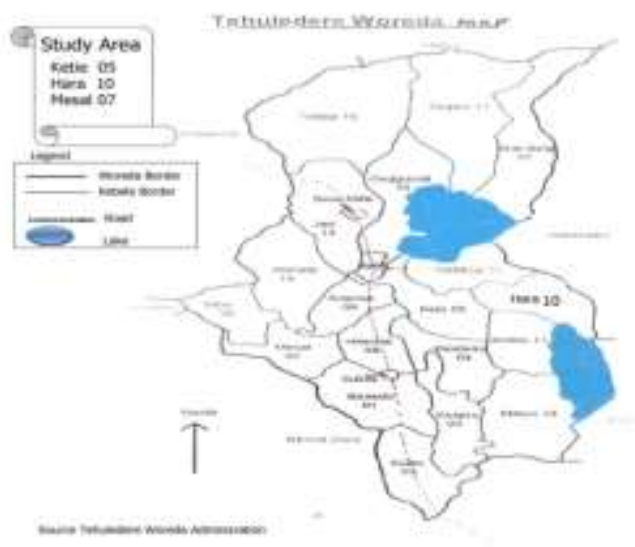

Fig.1 Map of Tehuledere woreda 


\section{SAMPLING AND SAMPLE SIZE}

The sample kebeles were selected from all agro-ecological zones of the woreda via purposive sampling. Kebele (010) Hara from "Kolla", kebele (05) Ketie from "Wina-Dega" and kebele (07) Mesal from "Dega" were selected on the basis of frequency of flood and drought occurrence in the kebeles of the woreda. The participants of this study included: the local people, government representative, and religious leaders of sample kebeles, and concerned officials from the woreda. The sample size was $300(10 \%)$ out of 3038 total house hold heads of sample kebeles. Stratified sampling technique used to get proportional sample size from each selected kebeles. Finally via available sampling the target respondents were selected and the questionnaire was administered in public meetings and the original home of respondents.

\section{Data Collection and Analysis Tools}

Triangulation approach was used in collection and analysis of the data. The data were collected via questionnaire, interview and document analysis.Thequestionnaire and interview items were developed byusing logical and psychometric methods. Majority of data, which collected via questionnaire were checked, coded and analyzed quantitatively by using different statistical techniques and the data which gathered by open ended questionnaire and interview analyzed qualitatively.

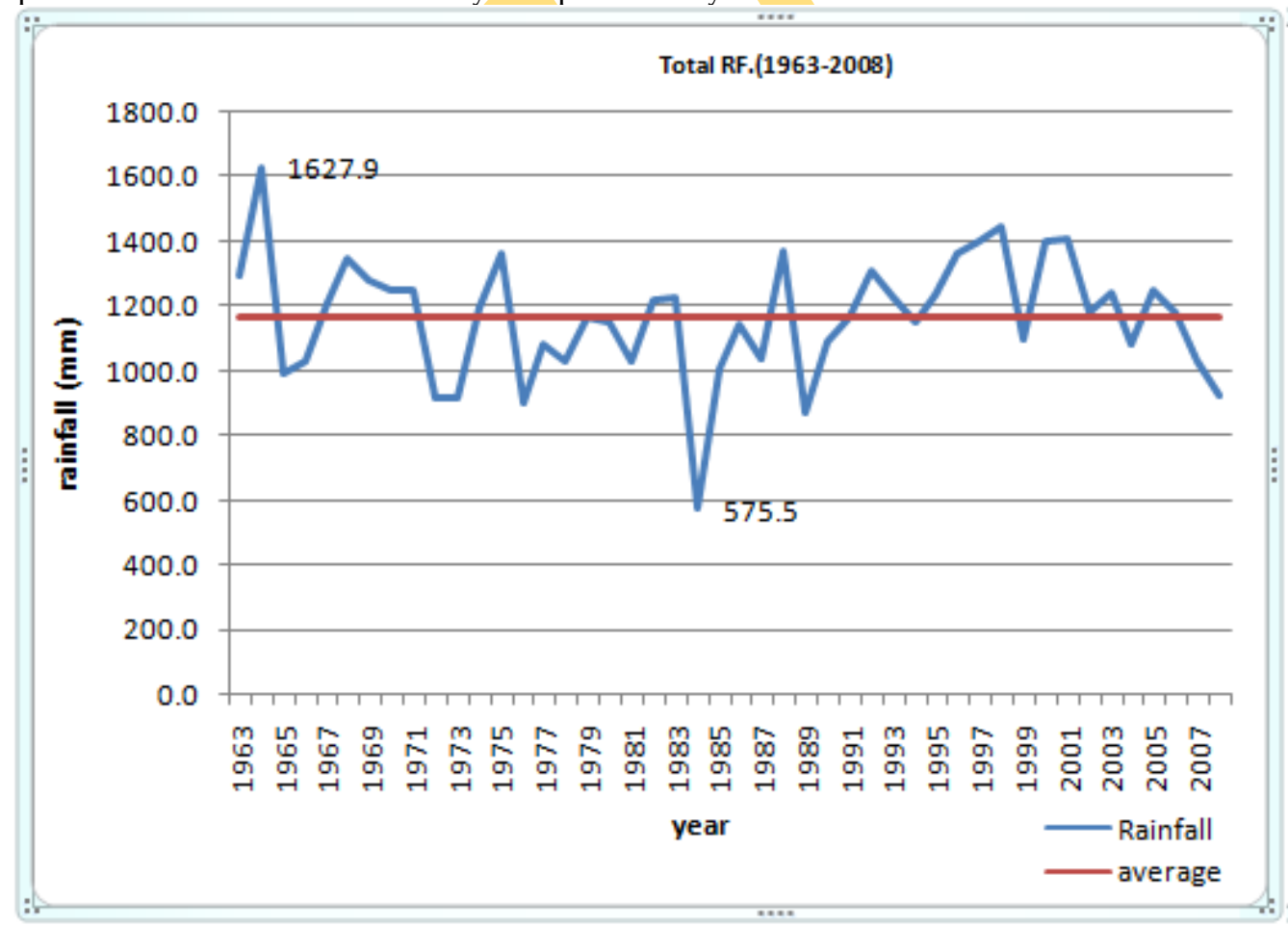

Fig.2.Total rainfall pattern of Tehuledere woreda from 1963-2008 


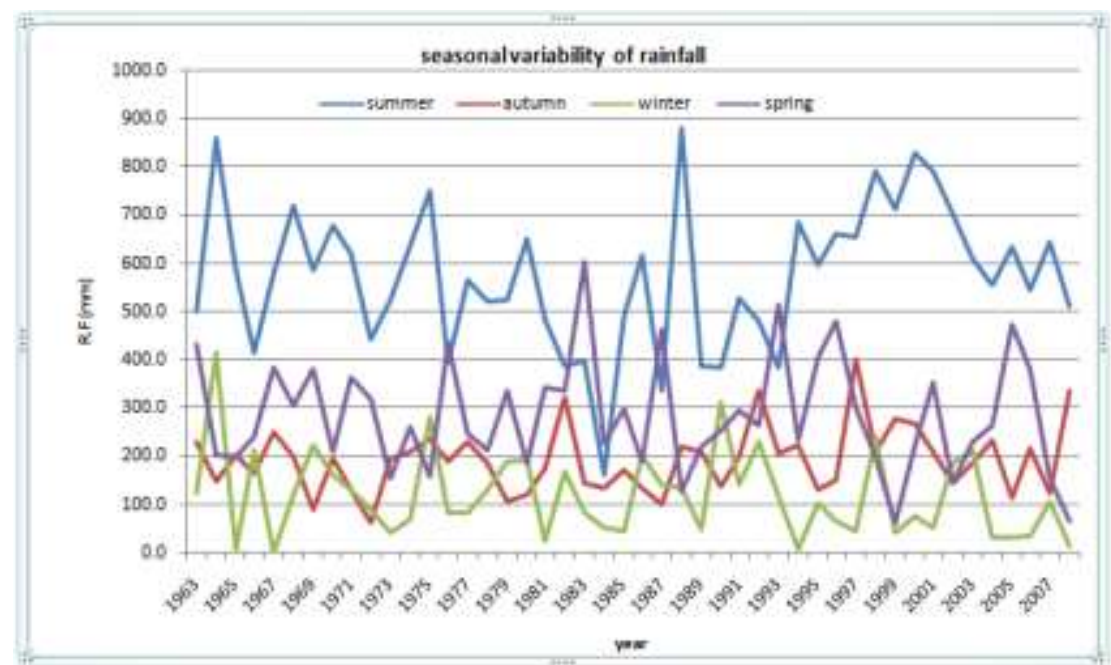

Fig.3 seasonal variability of Rainfall

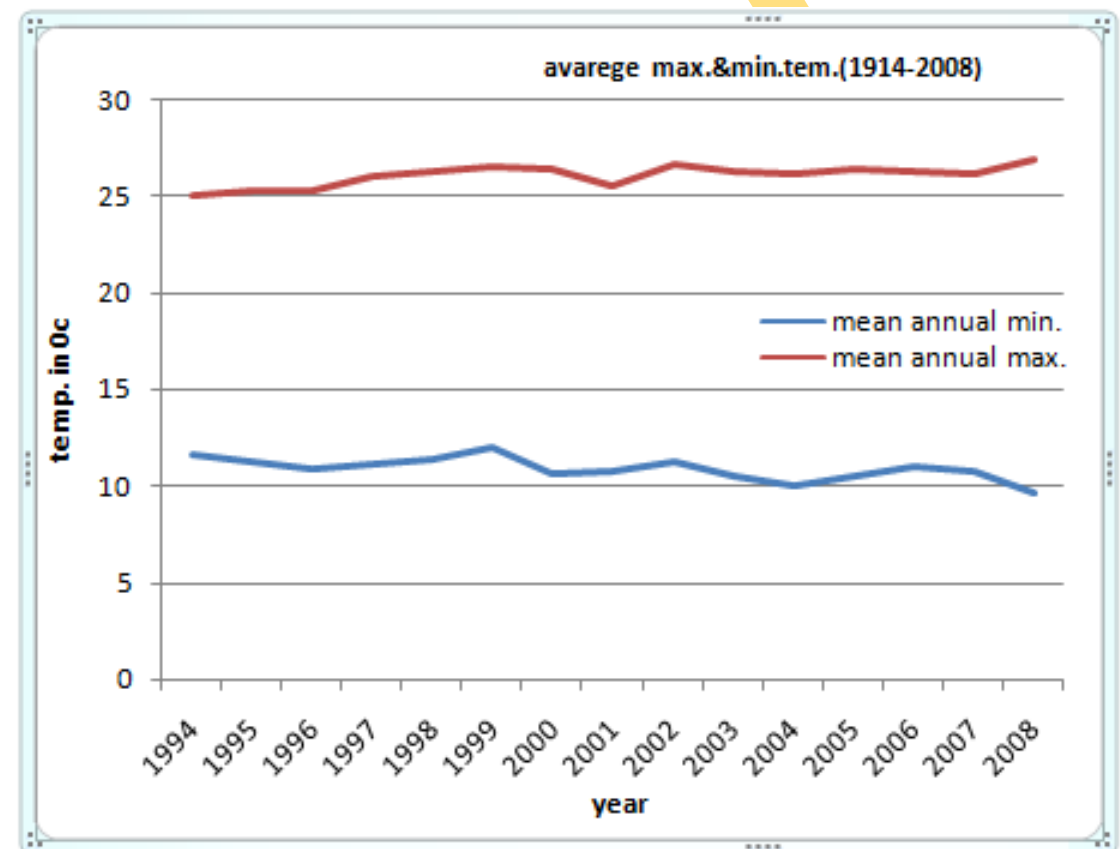

Fig.4 Mean max .and min. annual temperature of Tehuledere woreda from 1994 -2008 Source: - Ethiopian meteorological agency, Kombolcha branch, August, 2010

Regarding to the perception of community to climate variability, majority of participants $\mathrm{p}$ erceived the existence of the problem and their perception also related with their socio demographic variables.

The t-test shows, that there is relationship between educational level $(\mathrm{t}=11.751, \alpha=0.05, \mathrm{df}=398)$ and economic status $(\mathrm{t}=7.927, \alpha=0.05, \mathrm{df}=398)$ with perception of community to climate variability. Participants revealed that, they know the climate variability 
due to increasing of temperature $(62.2 \%)$, shortage of rainfall $(74.5 \%)$, unexpected heavy rainfall $(65.4 \%)$, recurring drought $(54.3 \%)$, \& flood, malaria territorial expansion, occurrence of new weeds and poor crop production yield in their respective kebeles.

\section{Community Perception to Causes Of Climate Variability}

Climate variability is caused by natural processes and anthropogenic activities, but many studies have shown that human activities taken the lion's share for the current climate variability. "The scientific proven causes include industrial pollution, deforestation, poor agricultural practices and destruction of natural resources" (Elliot et al., 2008).

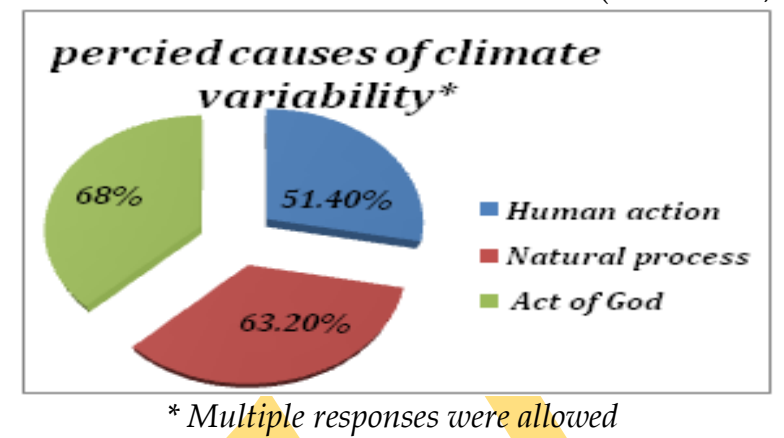

Fig. 5 perceived causes of climate variability by participants

$51.4 \%$ of respondents reflected that human activities are the cause of climate variability, which are deforestation(92\%), poor agricultural practices (42\%) and use of fossil fuel $(20.9 \%)$, where as $63.4 \%$ and $68 \%$ replied that the natural process and the reaction of God against to the evil activities of human being are the causes respectively(fig.5). The analysis depicts that majority of participants had limited knowledge about the causes, which may be due the local community are more concerned to their religion and lack of scientific information and knowledge.

\section{IMPACTS OF CLIMATE VARIABILITY}

Climate variability has adverse economic, social, health and environmental impacts. Majority of participants $(91.7 \%, 84.7 \%, 81 \%$, and $80.7 \%$ ) perceived that, drought, soil erosion, loss of crop and flood are common impacts of the climate variability in their kebeles respectively. According to the respondents, deforestation, degradation of grazing land, water pollution, diseases and destruction of pubic instructions are also the negative outcomes of climate variability in the study area (table 1$)$.

\begin{tabular}{|c|c|c|c|}
\hline \multirow{2}{*}{ No } & Impacts * & \multicolumn{2}{|c|}{ Participants } \\
\cline { 2 - 4 } & & Fre. & $\%$ \\
\hline A & Drought & 275 & 91.7 \\
\hline B & Soil erosion & 254 & 84.7 \\
\hline C & Reduction of crop yield & 243 & 81 \\
\hline D & Flood & 242 & 80.7 \\
\hline E & Deforestation & 230 & 76.7 \\
\hline F & Loss of grazing land & 181 & 60.3 \\
\hline G & Water pollution & 164 & 54.7 \\
\hline H & Exposed to diseases & 92 & 30.7 \\
\hline I & Loss of public services (road, school, health center etc.) & 82 & 27.3 \\
\hline
\end{tabular}

* Multiple responses were allowed Table1. Perception to the Impacts of Climate Variability 


\section{Adaptation Strategies to Climate Variability}

Adaptation is one of the main ways in which societies can deal with climate variability, but it has relation with community perception and adaptation capacity. The study revealed that majority of the respondents understoodthe possibility to adapt the adverse effects $(75.8 \%, \mathrm{x}=$ 4.79, and $\mathrm{s}=2$. 52). The $\eta^{2}$ (eta) analysis show that, the respondents' perception to adaptationhadstrong correlation with theirperception to climate variability $(\mathrm{r}(243)=0.892(79.57 \%), \mathrm{p}>.05, \mathrm{df}, 241)$ and it had also direct relations with their perception to causes of variability $(\mathrm{r}(243)=0.726(52.71 \%), \mathrm{P}>0.05, \mathrm{df}, 241)$. The local people had their own traditional and modern adaptation strategies. The data indicated that majority of the respondents were cultivating different traditional crops (94\%) and used natural fertilizer $(81 \%)$ (See fig. 6). They also adjusted the production seasons with current climate condition (56\%). However, the participants were very poor in practicing of modern agricultural adaptation measures. This is due to their poor adaption capacities, i.e. lack of awareness to new agricultural inputs, weak economic status, lack of water for irrigation,poor of accessibility agricultural inputs, shortage of agricultural lands and lack of additional income sources for the households, limited access of public services, very low government and NGOs intervention.Generally, the magnitude and rate of current climate shock, combined with additional socio-demographic and environmental issues make community owned adaptation strategies ineffective and unsustainable.

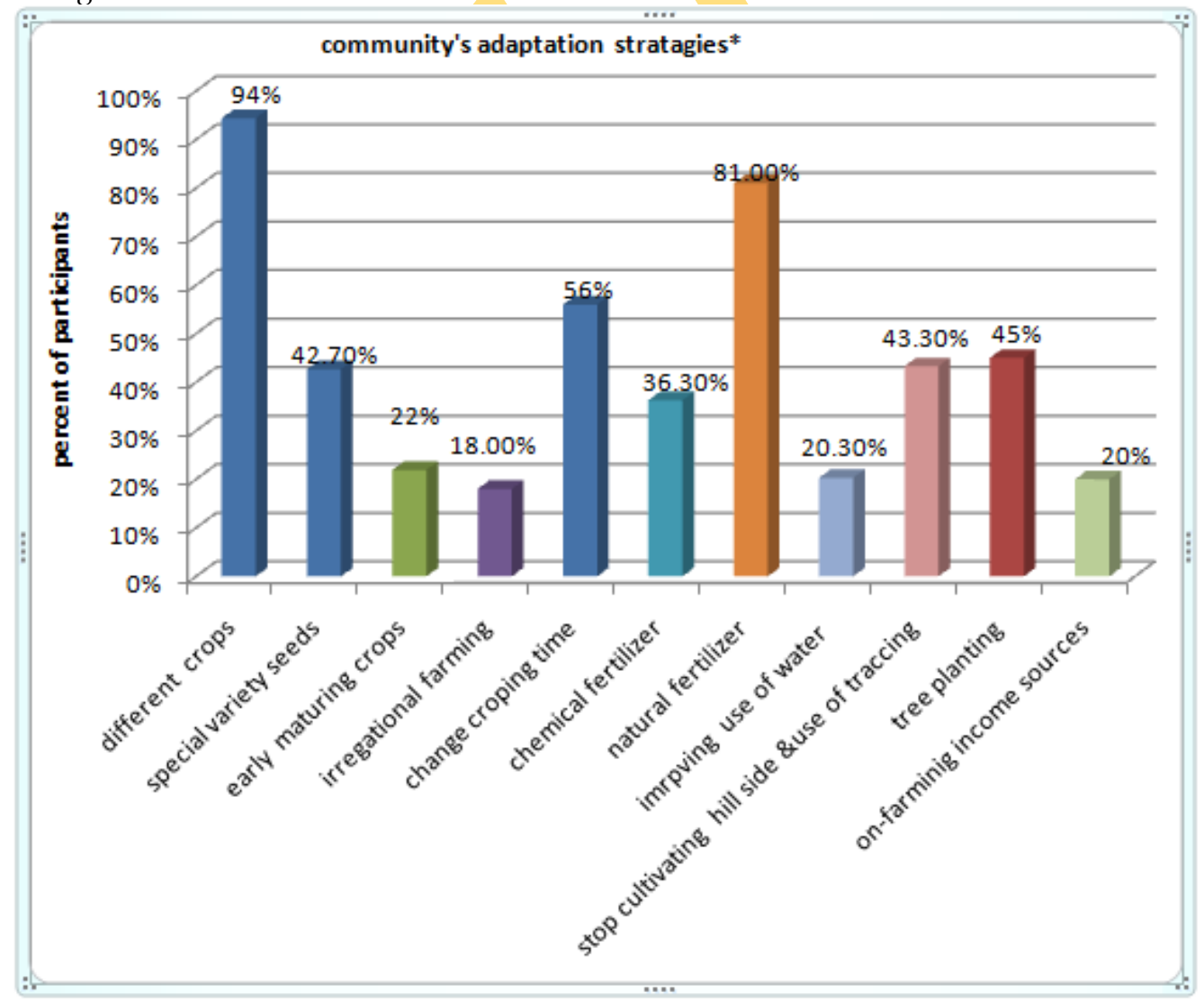

*multiple answers were allowedFig.6. Farmers' adaptation strategies to climate variability 


\section{ConCLusion AND ReCOMmendation}

This study was attempted to assess the community's perception, indigenous adaptation methods and adaptation capacity for the impacts of climate variability at Tehuledere woreda of South Wollo. Community perception is one of the inputs in the adaptation to climate variability.Most of the participants were perceived the existence of climate variability and the indicators, but more than half of participants linked the causes of climate variability with the act of God and the natural process of climate.Poor crop yields, death of livestock, expansion of diseases(malaria), migration of people from rural to urban, environmental problems (deforestation, loss of grazing land, soil degradation, water pollution and loss of public services) are the impacts of climate variability in the study area. The adaptation strategies of local community include:planting trees, soil conservation, cultivating different crops, use of natural fertilizer, adjusting crop seasons, fattening of cattle, use of special varieties seeds, use of chemical fertilizer and traditional irrigation during drought seasons. However the community had problems for effective adaption of impacts; which include lack of access to agricultural inputs, lack of irrigational farming,lack of information on climate incidences and adaptation measures, lack of capital, and poor infrastructures. In addition to this community's knowledge, population growth, shortage of agricultural land; natural resources degradation and recurring of poverty; limited government intervention make the adaptation process very weak. Lack of independent department, policy and budget to climate issues are additional burden in adaptation of climate variability in the study area.

Although the local community, government and NGOs have taken actions to improve the adaption capacity but it needs more efforts for effective and sustainable adaptation of the adverse effects on the local community. Therefore, effortsof all stakeholders should focus on improving the community's knowledge to climate variability through training, conference, extension services, and mass Medias. Participating the local community in environmental conservation programs, diversifying the livelihoods of farmers, introducing new agricultural inputs and technologies, expansion of irrigational agriculture, facilitating the availability of credit, constructing of public services, especially roads, health institutions, training Centre and markets, improving the genetic structure of livestock, involving of NGOs on the climate and related issues will improve and establishing independent climate institution and allocating budget increase the adaptation capacity of the local community.

\section{REFERENCE}

Belay Simane. (in press). Climate change: impacts and responses for carbon neutral and climate resilient Development in Ethiopia. Institute for water and development studies, college of development Studies, Addis Ababa University.

Block, J. Strzepek, K. Rosegrant, W., Diaoc.(2008). Impacts of considering climate variability

Elliott, B., Hudson, S., Parkyn, N. and Quinn, S. (2008). Climate change mitigation measures: Water quality benefits and costs. Report prepared byNIWA for MfE. Wellington: Ministry for the Environment.

IPCC(Intergovernmental Panel on Climate Change). (2007).Climate change, impacts, adaptation and vulnerability. Summary for Policymakers, Working Group II Contribution to the Intergovernmental Panel on Climate Change, Fourth Assessment Report.

Jotozo, Frank. (2010). Prerequisites and limits for economic modeling of climate change impacts and adaptation. Environmental economics research, 55, 1-13.

NAPA (National Adaptation Programme of Action), (2007). Climate Change National Adaptation Programme of Action (NAPA) of Ethiopia, Addis Ababa,June, 2007. 
on investment decisions in Ethiopia. International Research Institute for Climate and Society, ColumbiaUniversity, Lamont Campus. Agricultural Economics, 39, 171-181.

Thomalla,F. Downing, T. Spanger, E. Han, G.andRockström, J. (2006). Reducing hazard vulnerability: towards a common approach between disaster risk reduction and climate adaptation. Disasters, 2006, 30(1), 39-48.

UNEP (United Nations Environment Programme), (2006). Climate change and variability in the Sahel Region: Impacts and Adaptation Strategies in the Agricultural Sector. 17, 145-168.

UNISDR (United Nation International strategy for disaster reduction) (n.d.). Climate change and disaster reduction.( Briefing note 01)./ www.unisdr.org/climate-Change/.

Yohannes Gebre Michael and Mebratu Kiffle, (2009). Local innovation in climate change adaptation by Ethiopian pastoralists. Prolinnova-Ethiopia and pastoralist forum Ethiopia, Final Report.

Ziervogel, G. and Calder, R. (2003). Climate variability and rural livelihoods: assessing the impact of seasonal climate forecasts in Lesotho._, 35(4), 403-417.

\section{CALl For PAPER}

American Journal of Trade and Policy

(AJTP) is an open-access, peer-reviewed interdisciplinary journal which seeks articles from any broad theme of international trade.

AJTP features reports on current developments in international trade as well as on related policy issues. The digital online version is published by AJTP, and the hard copy (print) version is published by Asian Business Consortium (ABC). Web:
Asia Pacific Journal of Energy and Environment (APJEE) is a peer-reviewed multi-disciplinary international journal devoted to academic advanced research from the energy and environment arena. It specializes in the publication of comparative thematic issues as well as individual research articles, review essays, and book reviews. APJEE is fully and freely accessible on line. Web: www.apjee-my.weebly.com 